\section{THE SCHOOLBOY; A study of his nutrition, physical development and health.}

By G. E. Friend, M.R.C.S., L.R.C.P., with a foreword by Prof. J. C. Drummond, W. Heffer \& Sons, Ltd., Cambridge. 1935. Price 7/6.

Dr. Friend has undoubtedly done a great service not only to the schoolboy but also to the science of nutrition by the publication of this careful and prolonged study. The book, too, has appeared at a most opportune time, for the subject is one on which the public conscience has been roused and concerning which there is much, unfortunately too much, loose talking. Hence the record of the results of a systematic investigation of the population of a wellknown school (Christ's Hospital) over the long period of 20 years is specially valuable. Fortunately for the investigation the period of study embraced the years of the Great War when food rationing was enforced, so that the effect of a restricted diet as well as a more liberal diet both in quantity and quality, which had been instituted during the later years, is to be observed.

The author has set himself the task of correlating the development, nutrition and health of the boys with their diet and general hygiene. Detailed information regarding the diet and physical exercise on the height, weight and chest expansion of the boys as well as on the incidence of various diseases is supplied in the form of innumerable tables and charts so that the reader has no difficulty in forming his own conclusions, although the author's discussions are always illuminating. Roughly, the period of study is divided into four periods, 1 pre-war, 2 during the war, and 3 and 4 post-war, all of which present fundamental differences in the quantity and quality of the diet provided.

We agree with the author that his findings reveal that the average height and weight of the boys were greatest during the period of most liberal feeding especially so far as the absolute amounts of fat and protein, and particularly the relative amounts of those of animal origin, are concerned. Curiously, however, the health of the boys did not show a corresponding improvement.
Indeed, for illnesses such as chills, colds and we would specially mention septic conditions, there was a much higher percentage incidence during the years when the largest amounts of vitamin $A$ and D were in the diet. We were also struck by the frequency of what was diagnosed as influenza during these same years of liberal feeding, and that during this same period of maximum vitamin administration the complications of the influenzal attacks were most numerous. But perhaps the most striking fact which emerged, so far as the health of the boys was concerned, was the great increase in bone fractures during the period of enforced rationing when margarine instead of butter was being used in the dietary. These facts only show the complexity of the question and the need for more studies like that of Dr. Friend before we can draw any definite conclusions. One, however, at times wonders if school studies are the most suitable for the purpose and are not bound to disclose anomalies, because the subjects spend so much of their time at home when the dietary and other conditions are not under control.

\section{PHYSICAL DIAGNOSIS.}

By R. C. Cавот. Eleventh Edition. Baillière, Tindall \& Cox, London. 1934. 22/6.

Any book which reaches its eleventh edition must necessarily be meeting a desired want and has obtained such a hold on the student of medicine that it should require nothing more from the Reviewer than a mere mention of its appearance. In this edition opportunity has been taken to introduce recent developments in methods of investigation, e.g., in connection with coronary thrombosis, the measurement of cardiac reserve and intrathoracic neoplasms, and radiology in pulmonary tuberculosis receives fuller attention in this edition than the preceding one.

The information and views are expressed in a most direct fashion, the type is good and clear and there is a wealth of appropriate illustrations, those dealing with the physiognomy of disease being especially informative. We are glad to see that in the discussion of percussion the author favours the light stroke, though we regret 